\title{
Arca-Arca Wisnu Di Asia Tenggara (Abad Ke 4-8 M)
}

Sri Utami Ferdinandus

Keywords: statue, hindu, iconography, distribution, Southeast Asia

\section{How to Cite:}

Ferdinandus, S. U. Arca-Arca Wisnu Di Asia Tenggara (Abad Ke 4-8 M). Berkala Arkeologi, 15(3), 185-192. https:// doi.org/10.30883/jba.v15i3.693

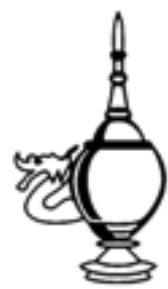

\section{Berkala Arkeologi}

https://berkalaarkeologi.kemdikbud.go.id/

Volume 15 No. 3, 1995, 185-192

DOI: $10.30883 /$ jba.v15i3.693

\section{cc) (1) (9)}

This work is licensed under a Creative Commons Attribution-NonCommercialShareAlike 4.0 International License. 


\title{
ARCA-ARCA WISNU DI ASIA TENGGARA \\ (Abad ke 4-8 M.)
}

\author{
Sri Utami Ferdinandus \\ (Jurusan Arkeologi FS-UI)
}

\section{Pendahuluan}

Dengan masuknya pengaruh Hindu-Buddha di Asia Tenggara pada permulaan Masehi muncullah kerajaan-kerajaan bersifat Hindu di Asia Tenggara pada abad ke $5 \mathrm{M}$. Dengan masuknya pengaruh Hindu dan berdirinya kerajaan-kerajaan Hindu di Asia Tenggara seperti di Jawa, Kalimantan (Taruma, dan Kutei), Pagan (Burma) dan Funan (Kamboja) didapatkan peninggalan arcaarca dan bangunan-bangunan suci yang tersebar di Asia Tenggara.

Dalam kertas kerja ini kami tertarik dengan adanya arca-arca Wisnu yang didapatkan di Asia Tenggara seperti arca-arca Wisnu yang ditemukan di Thailand dan Indonesia pada tahun 1951 . 1970. Kemudian pada tahun 1994 di Bangka dekat lokasi penemuan prasasti Kota Kapur ditemukan sebuah arca Wisnu dengan sebuah bangunan suci serta temuan lainnya (Pierre Yves Manguin 1994).

Arca-arca Wisnu tersebut mendapat perhatian dari para sarjana Eropa seperti Boisselier (1959). Stanley O'conor (1971), Wales (1935), dan Dupont (1941) serta beberapa sarjana Indonesia antara lain Wirjosuparto (1963),Edi Sedyawati (1963) dan Peter Ferdinandus $(1994,1995)$.

Arca-arca Wisnu yang akan dibicarakan dalam kesempatan ini adalah arca Wisnu yang masih dikenal atributnya seperti Jaiya, Dharma-ja, Oc-Eo, Wieng Sra, Sating Pra, Petburi, Ci-buaya 1 .II dan Bangka.

\section{Permasalahan}

Arca-arca tersebut pernah diteliti oleh para sarjana tersebut di atas. Dari penelitian mereka, dapat diamati bahwa sebagian besar hasil penelitian para sarjana, untuk mendapatkan periodisasi arca-arca Wisnu yang dilakukan dengan melihat ciri-ciri gaya, hiasan, porposi badan dan atribut sepintas lalu. Mengapa kami sebutkan sepintas lalu sebab tidak diperhatikan perkembangan atribut sampai hubungannya dengan tokoh dewa tersebut.

Wiryosuparto (1963) memperhatikan bahan dan ciri-ciri arca. Peter Ferdinandus $(1994,1995)$ mendasarkan perbandingan sejarah atribut tokoh dewa di India dan arca-arca di Indonesia.

Dengan adanya perbagai metode penelitian ikonografi oleh beberapa sarjana dalam kesem- patan ini kami mencoba meneliti kembali arcaarca Wisnu terutama di Thailand berdasarkan pendekatan perbandingan sejarah atribut tokoh dewa Wisnu.

\section{Metode Penelitian}

Dalam estetik Hindu sebagai pembatas ni-lai keindahan adalah konsep sadrsya dan pra-mana (Anad,1933:203-8). Kedua konsep terse-but dipakai sebagai dasar keindahan pengarca-an dalam kitab-kitab Hindu yang tidak didapat-kan pada masa Jawa Kuna. Meskipun demikian seperti dikatakan oleh Edi Sedyawati Hadimulyo (1979:1152) perlunya diperhitungkan kemungkınan golongan pemahat dan golongan penulis bersama-sama mengikuti suatu tradisi suci berkenaan dengan gagasan-gagasan dasar kedua pihak untuk tidak melanggar.

Apakah yang menjadi gagasan dasar dari sebuah arca dewa?. Apabila gagasan dasar konsep kedewaan bagi arca adalah sadrya (lambang kedewaan) dan pramana (ukuran) mengapa konsep dasar ini tidak didapatkan di Indonesia?. Kalau diperhatikan arca-arca Wisnu di Asia Tenggara temyata atribut-atribut Wisnu dan mahkota tidak berubah meskipun mengalami variasi. Oleh sebab itu kami berpendapat konsep dasar kedewaan adalah atribut-atributnya.

Menurut Naditha Krishna (1980) untuk mengerti ikonografi Hindu adalah menganalisa tiap atribut dengan mendetail sebab setiap atribut mempunyai latar belakang lingkungan dan mitologi. Spence (1921) berpendapat bahwa mitologi adalah dasar ilmu pengetahuan manusia masa lampau sebagaimana dijelaskan alam lingkungannya. Penelitian Nanditha mengenai ikonografi Wisnu-Narayana di India memberi gambaran atribut-atribut Wisnu dan tokoh Wisnu merupakan satu kesatuan, sejarah perkembangan tersendiri, dan latar belakang hubungan dengn kehidupan sosial masyarakat India dengan Asia Tenggara.

Perkembangan arca-arca Wisnu di India menunjukkan hiasan ciri utama tokoh Wisnu adalah mahkota dan wahana. Mahkota merupakan suatu tanda kemuliaan seorang tokoh dewa. Cerita mitologi Wisnu (Ramayana dan Mahabharata) umumnya dihubungkan dengan seorang raja pembasmi kejahatan sehingga mahkota meru- 
pakan ciri utama seorang raja dalam pengarcaan atau relief. Ciri ini didapatkan juga di Asia Tenggara. Wisnu selalu bermahkota kiritamahkota. Oleh sebab itu dalam penelitian ini juga diperhatikan bentuk mahkota Wisnu.

Menurut cerita Mahabharata, wahana Wisnu adalah Garuda. Dalam kertas kerja ini tidak akan dijelaskan mengenai bentuk-bentuk garuda sebab arca-arca Wisnu yang dijelaskan tidak berwahana.

\section{Analisa}

Arca-arca Wisnu tertua didapatkan dalam Mahabharata bertangan dua dan memegang cakra dan sangkha (Desai, 1973:7). Menurut naskah Wisnudharmottara arca Wisnu bertangan dua beratribut cakra dan gada. Jumlah tangan Wisnu berkembang sampai berjumlah 8 . Bertangan 4 beratribut sangkha, cakra, gada, dan padma disebutkan dalam Wisnudharmotara, III. 60.2,85,10-11. Penelitian Nanditha Krishna (1980:88) menunjukkan arca Wisnu tertua tidak mengikuti kitab-kitab agama.

Mitologi Wisnu didapatkan pertama kali dalam kitab Rig Weda yang menyebutkan sebagai dewa Aditya atau matahari, pelindung dan kemudian dalam Mahabharata sebagai dewa pelindung dan menjadi dewa utama (Mahabharata, $V$. 9.298). Perkembangan dewa Wisnu berkem-bang bersama perkembangan atributnya. Tokoh Wisnu kemudian dipuja oleh masyarakat India sebagai pemelihara dan pelindung

Wisnu mempunyai peranan penting di Asia Tenggara seperti di Kamboja dan Indonesia. Beberapa raja-raja menyatakan dirinya seperti Wisnu bahkan Airlangga menyebutkan dirinya sebagai jelmaan Wisnu. Dengan berkembangnya pemujaan kepada Wisnu maka tidak dapat diragukan arca-arca Wisnu mempunyai peranan penting dalam pemujaan raja-raja di Asia Tenggara. Meskipun pemujaan Wisnu dikenal di Asia Tenggara bukan berarti sistem pemujaan tokoh dewa di India akan diambil semuanya termasuk pembuatan arca. Pembuatan arca tidak lepas dari seniman. Dalam membuat arca seniman mempunyai kebebasan tersendiri. Meskipun demikian unsur-unsur dasar sebuah arca dewa tidak dapat diubah sekehendak hati. Sebab akan mengurangi nilai-nilai kesakralan seorang tokoh dewa. Jika diperhatikan, arca Wisnu sebagai dewa ternyata bentuk wajah dan hiasannya tidak menunjukkan ciri-ciri dasar tetapi hanya atributatributnya. Oleh sebab itu dalam uraian selanjutnya akan diperhatikan atribut sangkha, cakra, gada, dan padma.

\subsection{Sangha}

Sangkha adalah kerang laut yang pertamakali dipergunakan masyarakat Harapa untuk keperiuan sehari-hari seperti untuk hiasan, mangkuk, sendok (Vats 1940). Kemudian sangkha dipergunakan untuk alat tiup untuk berkomunikasi (Brhadaranyaka Upanisad, II.4.8, IV.58.10).

Wisnu pertamakali dihubungkan dengan sangkha didapatkan dalam kitab Mahabharata dan Ramayana. Dalam Ramayana, sangkha dipergunakan Rama dalam perang melawan tentara Rawana (Ramayana,VI.33) dan dalam Mahabharata sangkha dipergunakan oleh Kreshna dengan nama Panchajanya (Mahabharata 1.220. 7941). Kemudian sangkha dihubungkan dengan unsur keagamaan. Bunyi sangkha dipergunakan mengusir unsur roh-roh yang jahat (Nandita Krishna 1980:35)

Bentuk sangkha tertua yaitu pada abad $2 \mathrm{M}$ digambarkan agak membulat dan dipegang oleh tangan kiri. Pada masa Gupta sekitar abad $4 \mathrm{M}$ hiasan spiral sangkha selalu digambarkan pada bagian atas. Jika kami perhatikan sikap dan bentuk sangkha yang dipegang pada masa Gupta ternyata didapatkan pada arca-arca dari Jaiya. Nagara Sri Dharmaraja (Ligor) dan Oc-Eo.

Selanjutnya dari hasil perbandingan arcaarca Wisnu di India, arca-arca Wisnu di Vieng Sra, Sating Pra dan Cibuaya I dan If menunjukkan persamaan dengan arca-arca masa Pallawa dan Chalukya dari abad 7/8 M. dalam sikap memegang sangkha.

\subsection{Cakra}

Dalam Rig weda I.II8.2.157.3,164.3, 12 cakra dipergunakan untuk roda kereta dan pada Rig Weda VIII.96.9 sebagai senjata Indra. Cakra mulanya merupakan senjata alat perang yang dipergunakan para dewa maupun para asura. Tetapi dalam Mahabharata disebutkan sifat cakra sebagai bumerang yang kembali ketangan sipelempar (Mahabharata,ł.225.8199). Nandita Krishna (1980:42-44) menjelaskan bahwa senjata ini didapatkan pengaruh dari masyarakat Kallar dan Marawar. Kemungkinan suku bangsa ini memberi tokoh Wisnu beratribut cakra.

Pada masa Kushana, cakra dipegang tangan kiri depan dalam bentuk roda, kemudian masa Gupta masih dalam bentuk roda tetapi sikap tangan yang bervariasi. Unsur masa Kushana dan Gupta ternyata tidak didapatkan pada arca-arca Wisnu di Asia Tenggara.

Selanjutnya bentuk dan sikap cara memegang cakra masa Pallawa dan Chalukya dari periode abad 7/8 M dipegang bagian ujungnya, dan berhias sederhana. Unsur-unsur ini diperlihatkan pada arca-arca Jaiya, Sating Pra, Petburi, Cibuaya I, dan II. Dari sikap tangan yang 
diperlihatkan pada arca Wisnu dari Bangka kemungkinan besar memegang cakra (cakra hilang).

\subsection{Gada}

Gada merupakan sebuah tongkat sebagai senjata oleh masyarakat pada masa prasejarah. Wisnu juga memiliki gada dengan sebutan Kaumodaki yang didapatkan dari dewa Waruna. Oleh sebab itu Wisnu juga bernama Kumodaka yang berarti bunga bakung.

Bentuk pada arca-arca Wisnu mulanya seperti gada yang dipergunakan oleh raja Kushana. Bentuk ini ternyata mendapat pengaruh dari Yunani yang sering dipegang oleh Hercules yang melambangkan unsur kekuasaan. Arca-arca Wisnu pada masa Gupta abad $4 \mathrm{M}$ bentuk gada agak membulat seperti gada masa Kushana. Sikap memegang seperti bersandar pada gada. Sikap dan bentuk ini diperlihatkan pada arca-arca di Wieng Sra, Petburi, Cibuaya I dan II. Sedangkan arca-arca lainnya dalam keadaan patah.

\subsection{Padma}

Bunga padma sebenarnya merupakan bunga yang populer di India dan telah dikenal pada masa Rig Weda. Pada lukisan amulet yang ditemukan di Mohenjodaro didapatkan seorang wanita memegang padma bertangkai yang melam. bangkan dewi ibu (Nandita Krishna 1980:60).

Pada arca-arca Wisnu yang tertua tidak didapatkan atribut padma melainkan hanya sangkha, cakra dan gada. Wisnu beratribut padma baru terlihat pada masa Gupta sekitar abad ke 4.

Bentuk padma berbentuk bulat seperti bunga yang belum berkembang. Bentuk ini temyata didapatkan pada arca-arca Oc-Eo, Sating Pra, Cibuaya I dan II sedangkan arca-arca lainnya tidak dikenal sebab keadaan arca seba-gian dari tangan arca hilang. Sebuah fragmen tangan di lokasi penemuan arca Wisnu dari Bangka memegang padma berbentuk bulat seperti pada masa Gupta

\subsection{Mahkota}

Mahkota sebenamya bukan atribut Wisnu meskipun demikian karena Wisnu selalu dihubungkan dengan raja-raja, maka ciri utama bentuk mahkota adalah bentuk selinder meninggi atau kirimahkota. Dari bentuk ini dikenal dua jenis yaitu: a) berbentuk selinder meninggi bagian atas mengecil; b) berbentuk selinder tetapi bagian atas membesar.

Ciri mahkota berbentuk selinder meninggi dan mengecil didapatkan pada arca-arca Wisnu pada masa Gupta sekitar abad ke $4 \mathrm{M}$. (Nanditha Krishna 1980:94).

Ciri mahkota berbentuk selinder dan mengecil di dapatkan pada arca-arca Wisnu di Asia Tenggara kecuali arca Wisnu dari Cibuaya II. Wieng Sra, Suratradhàni dab Takuo. Meskipun ada persamaan dalam bentuk tetapi perbedaan adalah dalam hiasannya. Arca-arca Wisnu dari Bangka dan Thailand hampir tidak ber hias. sedangkan arca Cibuaya I berhias Jika diperhatikan mahkota arca Wisnu Cibuaya II bentuknya seperti selinder meninggi tetapi membesar pada puncaknya. Bentuk ini mengingatkan arca-arca Wisnu di India yang mendapat pengaruh dari Persia dan dipakai para seniman dari Pala pada abad ke $8 \mathrm{M}$ (Nanditha Krishna, 1980, foto 28).

\section{Penutup}

Sejarah perkembangan atribut pada arcaarca Wisnu di India masa Gupta (abad 4 M) berperanan penting dan kemudian berkembang ke Pallwa dan Chalukya (abad 7/8 M)

Dengan adanya data dari sejarah perkembangan dan dibandingkan dengan atribut-atribut arca-arca Wisnu di Asia Tenggara memberi gambaran bahwa atribut-atribut Wisnu di Asia Tenggara (Thailand dan Indonesia) tidak diterima sesuai dengan perkembangan di India. Beberapa atribut seperti padma dan sangkha dari masa Gupta tetap dipertahankan pada abad sesudahnya. Untuk jelasnya dapat dilihat pada daftar periodisasi atribut pada arca-arca Wisnu di Asia Tenggara.

Adapun periodisasi atribut pada arca-arca di Asia Tenggara adalah sebagai berikut

1. Arca Cibuaya I abad ke 4 - ke 7/8 M.

2. Arca Cibuaya II abad ke 4-ke $7 / 8 \mathrm{M}$.

3. Arca Bangka dari abad ke $4 \mathrm{M}-7 / 8 \mathrm{M}$.

4. Arca Jaiya dari abad ke 4-ke 7/8 M

5. Nagara Sri Dharmaraja abad ke 4- ? M

6. Oc-Eo abad ke 4 - ?

7. Viensra abad ke 4 - ke 7/8 M.

8. Sating Pra abad ke 4 - ke $7 / 8 \mathrm{M}$.

9. Petburi abad ke 4 - ke 7/8 M

10. Prasat Damres Krap abad ke-4 - ke-7/8 M

11. Than Hoa abad 4 - 7/8 M.

Dengan demikian dari uraian periodesasi atribut arca-arca Wisnu tersebut di atas didapatkan gambaran bahwa kemungkinan arca tersebut dibuat sebagai berikut.

1. Arca Wisnu dari Cibuaya I dan II diduga dari abad 8;

2. Arca Wisnu dari Bangka diduga dari abad $8 \mathrm{M}$

3. Arca Wisnu dari Jaiya diduga dari abad 8

4. Arca Wisnu dari Viensra diduga dari abad 8

5. Arca Wisnu dari Sating Pra diduga dari abad 8

6. Arca Wisnu dari Than Hoa diduga dari abad 8 
Sedangkan arca Oc-Eo dan Nagara Sri Dharmaraja tidak jelas karena keadaan atributnya sudah rusak. Dengan adanya persebaran arca-arca Wisnu di Asia Tenggara pada abad ke$8 \mathrm{M}$ kemungkinan besar pada masa raja-raja $\mathrm{Pa}$ lawa unsur Wisnuit berkembang di Asia Tenggara.

\section{KEPUSTAKAAN}

Boisselier, Jean. 1959. 'Le Visnu de Tjibuaya (Ja-va Occidental) et la Statuaire de Sud-Es. Asiatique. Artibus Asiae.XXII (3):210226

Desai,K.S.1973. The Iconography of Visnu New Delhi.

Dupont,Pierra.1941. Visnu entres de I"Indochine Occidentale BEFEO XLII(2);233-254

Edi Sedyawati.1963. Arca Wisnu Dari Tjibuaya. Skripsi.

Ferdinandus, Peter,Dkk. 1994.Laporan Penelitian Situs Cibuaya Puslit Arkenas. Inpress.

Ferdinandus,Peter.1995. Arca arca Wisnu dan Runtuhan Struktur Bangunan bata di Situs Cibuaya. Inpress.
Krishna, Nanditha.1980. The Art and Iconography of Vishnu-Narayana. Bombay.

Manguin,P.Y. DKk.1994. Kota Kapur (Bangka): A pre-Sriwijaya Hindu site in South Sumatra? dibawakan dalam Seminar European Association of Souteast Asian Archaeologists. Paris

O'Connor.J.Stanley,Jr.1971. Hindu Gods of Peninsular Siam. Artibus Asiae, Switzerland.

Spence,I. 1921. An Introduction of Mythology. London.

Vats,MS.1940. Excavation at Harappa New Delhi.

Wales,H.C. Quaritch. 1935.A New Explored Route of Indian Cultural Expansion: IALIX(1). $1-35$

Wirjosuparto,Sutjipto.1963. The Second Visnuimage of Cibuaya Madjalah Ilmu-ilmu Sastra: $170-186$. 


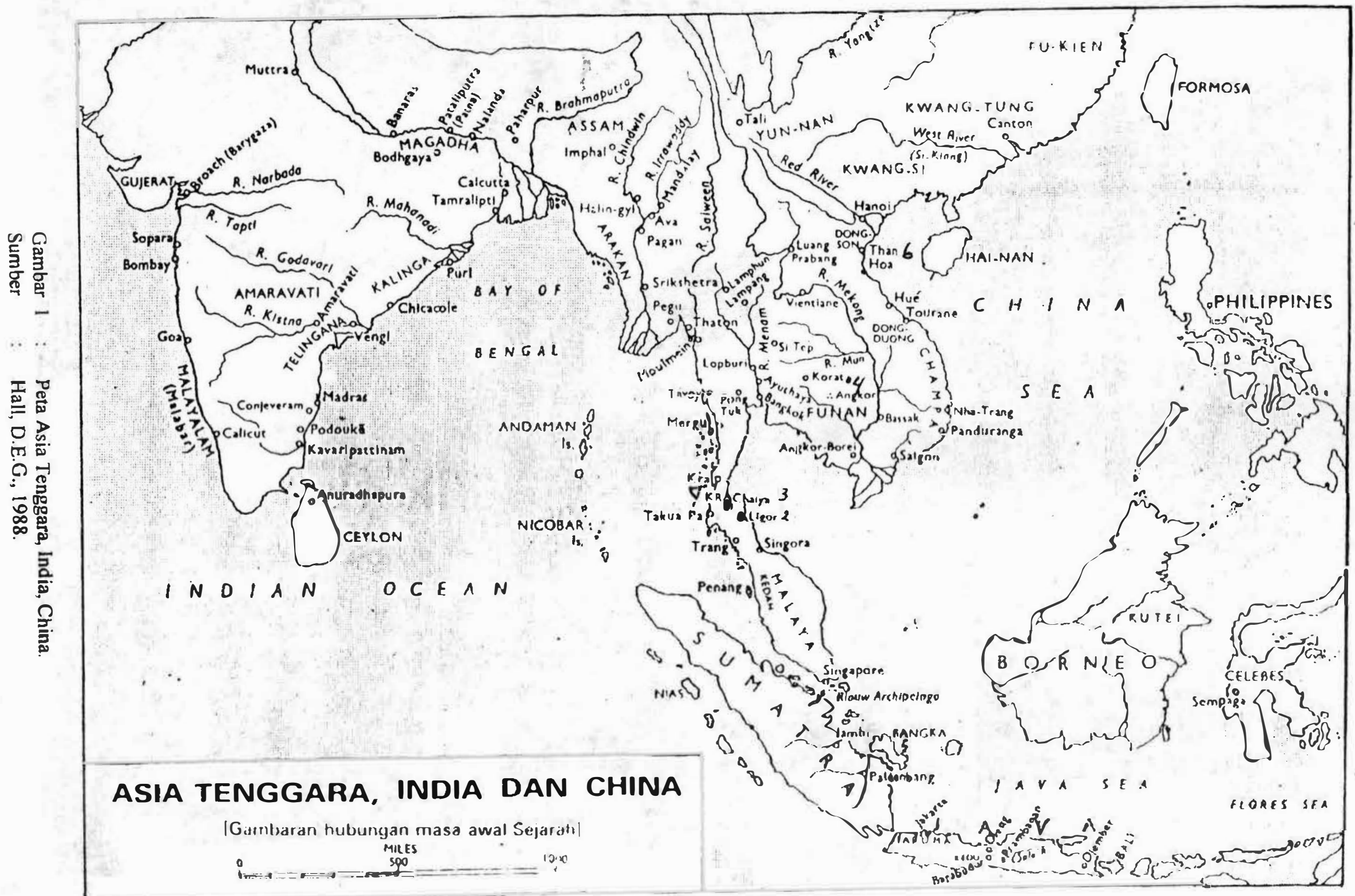



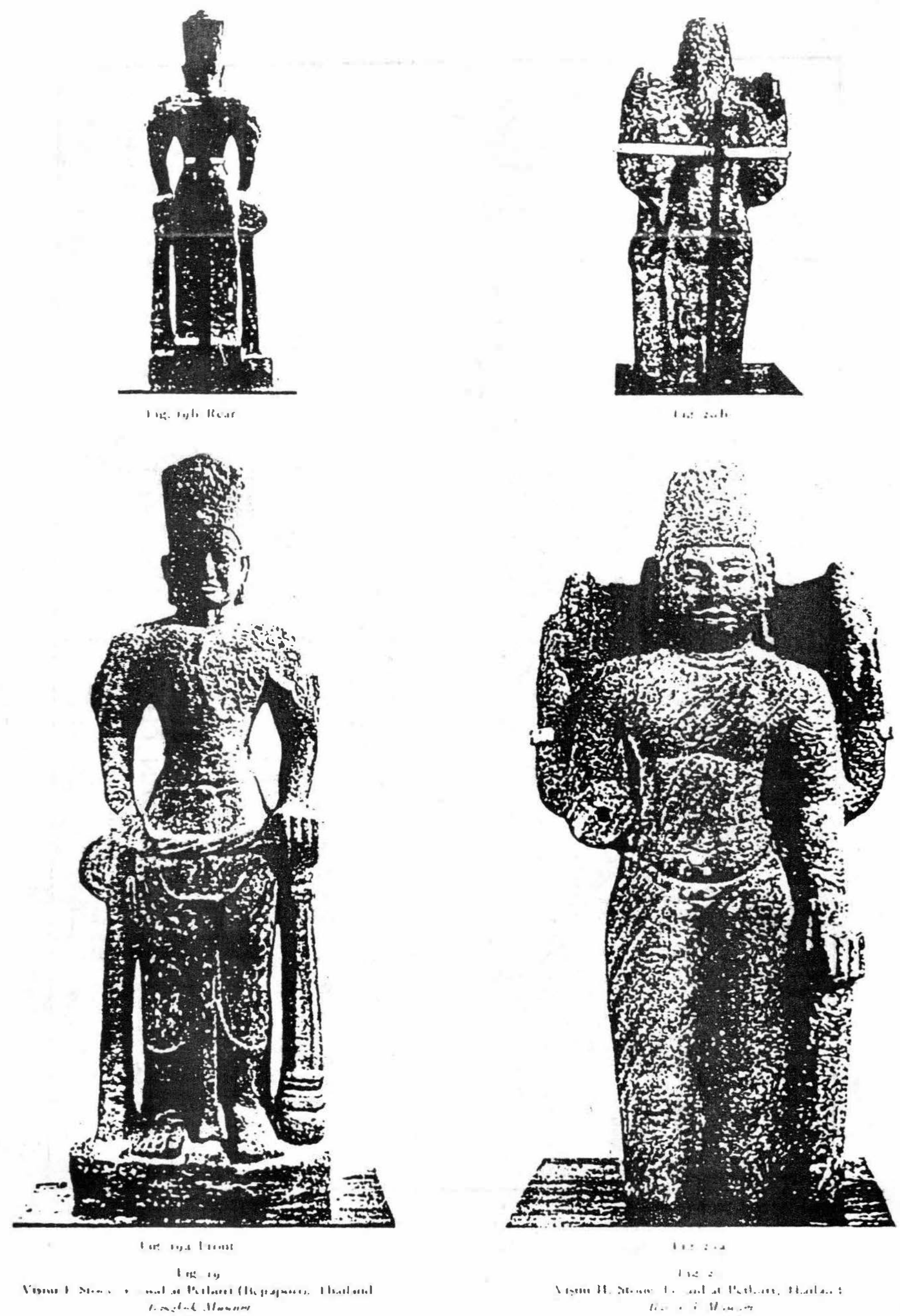


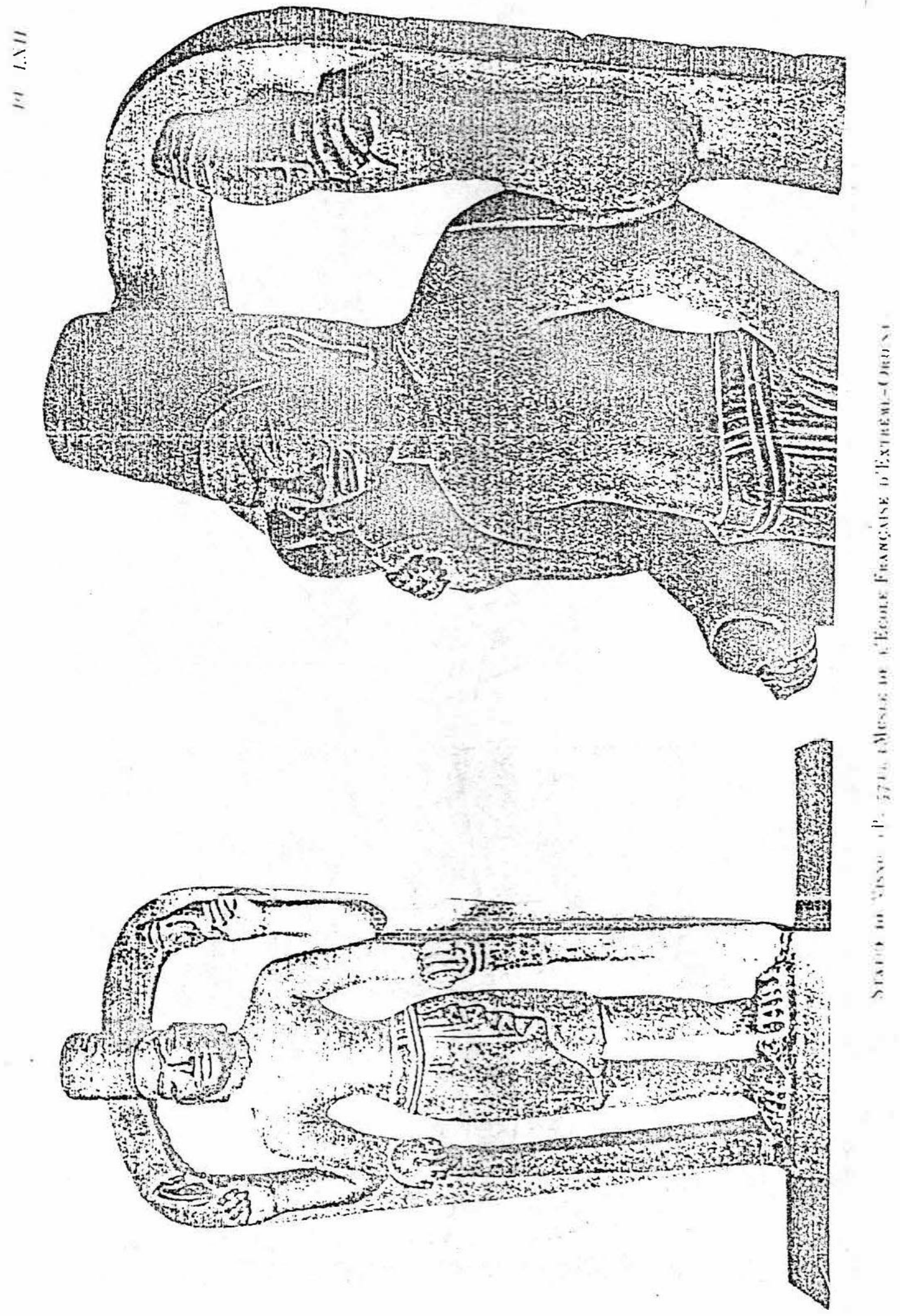




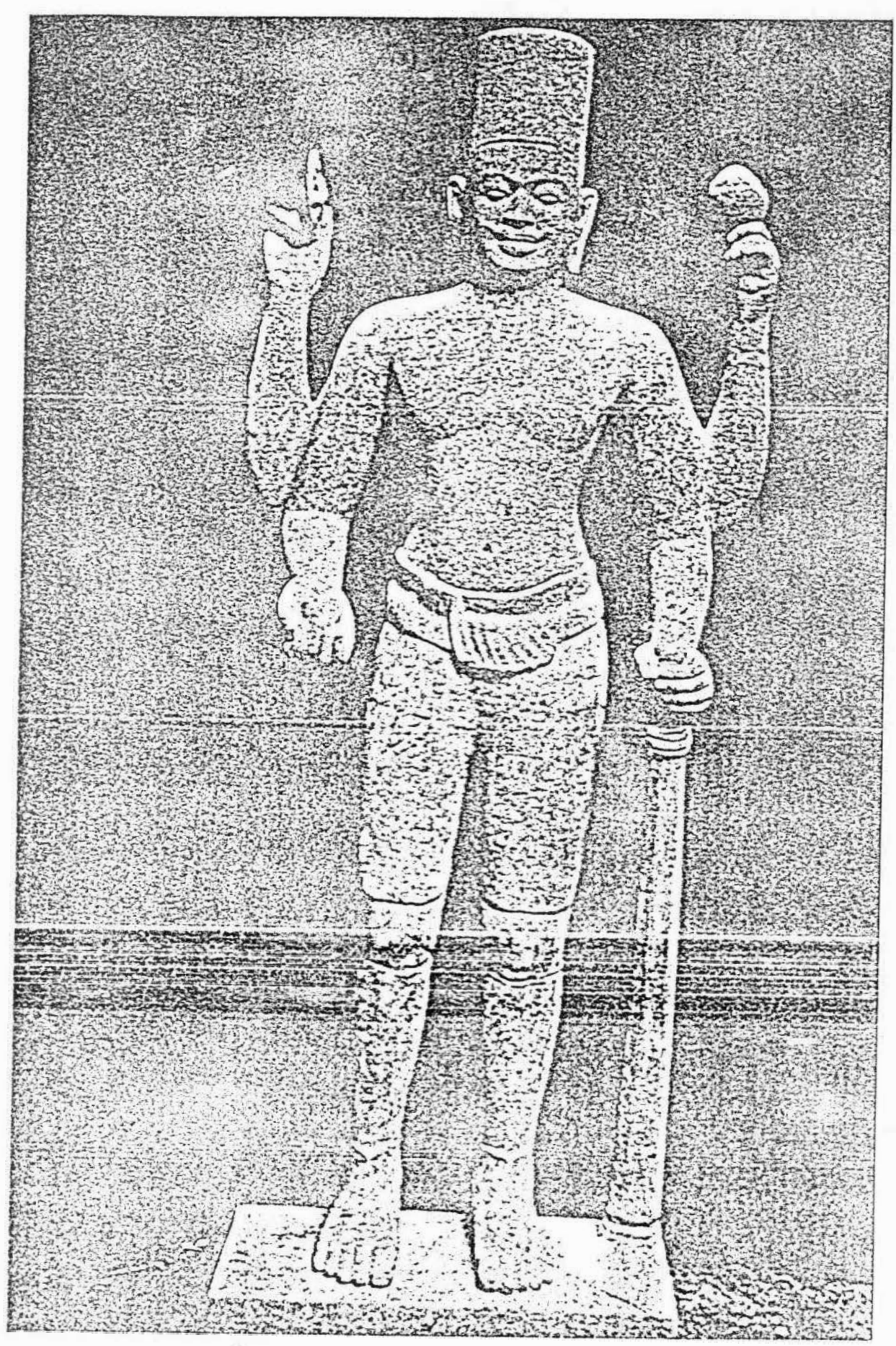

